\title{
Stress and periodontitis: A review.
}

\author{
DR. K. Malathi, M.D.S ${ }^{1}$, DR. Dhanesh Sabale, (M.D.S) ${ }^{2}$ \\ ${ }_{1,2}$ (Department of Periodontics, Tamil Nadu Government College, Chennai, India)
}

\begin{abstract}
Periodontal diseases are common chronic inflammatory diseases caused by pathogenic microorganisms which induce elevations of pro-inflammatory cytokines resulting in tissue destruction. Evolution of periodontal diseases is influenced by many local or systemic risk factors. Stress has been suggested as one of them and may negatively influence the outcome of periodontal treatment. The possible relationship between stress and increased susceptibility to periodontal disease is not completely understood.The aim of this review is to provide the relationship between psychological stress and periodontal diseases.
\end{abstract}

Key Words: Stress, Periodontal diseases, Immune system.

\section{Introduction}

Since 1950, emotional factor have been identified in periodontal disease. Stress is defined as a state of physiological or psychological strain caused by adverse stimuli such as physiological, mental, emotional, internal or external that tends to disturb the functioning of an organism and which the organism desires to avoid 1. The layman term to the "stress" is used to describe adverse emotional reaction to unpleasant experience. According to the stressful event, the body's way to respond to stress is by sympathetic nervous system activation which results in the fight-or-flight response. Stress typically describes a negative condition or a positive condition that can have an impact on a person's mental and physical well-being.

Stress is classified as a risk indicator for periodontal disease ${ }^{9,10, \text { and } 11}$. The most notable example is stress and acute necrotizing ulcerative gingivitis.

Stressor is any stimuli, situation or circumstance with the potential to induce stress reaction ${ }^{14}$. The effect of the stress response includes anxiety, depression, impaired cognition and altered self-esteem.

\section{Stress and Immune System:}

In a review, Biondi (2001) shows the impact of various psychosomatic conditions on the immune system. Stress can result in the down regulation of the immune system, mediated primary through the hypothalamus- pituitary- adrenal and sympathetic adrenal medullary axis ${ }^{15}$. The hypothalamic pituitary adrenocortical axis (HPA) and its end product, cortisol is thought to be important mediator of its relationship between stressful life experience and health outcome. The function of cortisol is to depress theimmune system by diminishing the IgAand IgG secretions.HPA response is a component of the organism's adaptive system for maintaining function under changing environmental circumstances.

The systemic reaction that affect the body (or) produce an interrelated nonspecific tissue change resulting from continued exposure to stress have been termed the general adaptation syndrome (GAS) ${ }^{12 .}$

The system is thought to be group of psychological mechanism that represent an attempt by the body to resist damaging effect of stress.

Three stages of syndromes have been identified

1. The initial response (The alarm reaction).

2. The adaptation of stress (The resistance stage).

3. The final stage marked by inability to maintain adaptation to stress (The exhaustion stage).

\subsection{Action of Cortisol:}

When activated by stress, hypothalamus releases corticotrophin releasing hormones into the level that commence the hypothalamus to the anterior pituitary. This triggers the anterior pituitary to secret ACTH hormone in to the blood stream. Once it reaches the adrenal cortex ACTH stimulates the release of glucocorticoid in the form of cortisol. The HPA axis is regulated in a complete negative feedback system with circulatory glucocorticoid inhibitory action.

Base line level of cortisol in humans is 10-6 $\mu \mathrm{g}$, but in morning hours $20 \mu \mathrm{g}$.In people who have normal routine of normal sleep and day time activity, cortisol level is $5 \mu \mathrm{g}$ between 10 p.m. to 4 a.m. (Fig.1) 


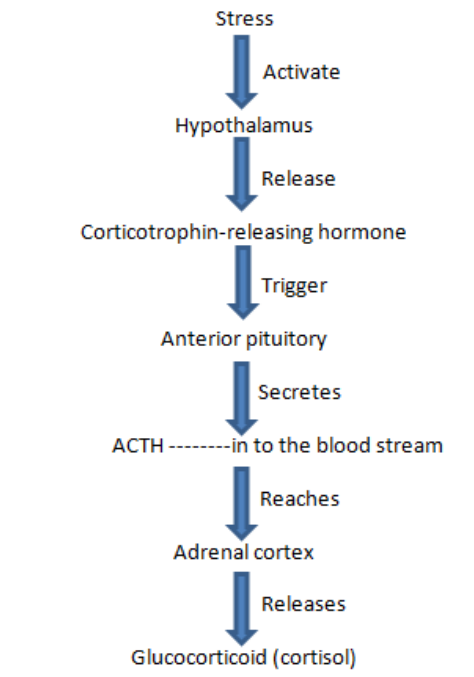

Fig: 1- mechanism of cortisol release upon stress

\subsection{Sympathetic nervous system:}

It is second pathway to be activated by stress in to sympathetic nervous system. Stress can act on autonomous nervous system by activating fibers to innervate tissues of immune system. The sympathetic nervous system has a role in regulatory immune cell activation ${ }^{2}$.

The activation of this system in stress is actually protective in, that it provides energy to deal with the stressor.All these immune response are critical for the normal immune-inflammatory response to "periodontal pathogens"

\subsection{Role of stress in periodontal disease:}

Stress influences the immune system and along with changes the behaviour, so it is very important to analyse if its influence is the same on the different forms of the periodontal disease. Stress decreases the saliva flow and increases the plaque formation. Studies have proven that thepsychosocial factors are predisposingfactors for the development of necroticperiodontitis. (Fig. 2)

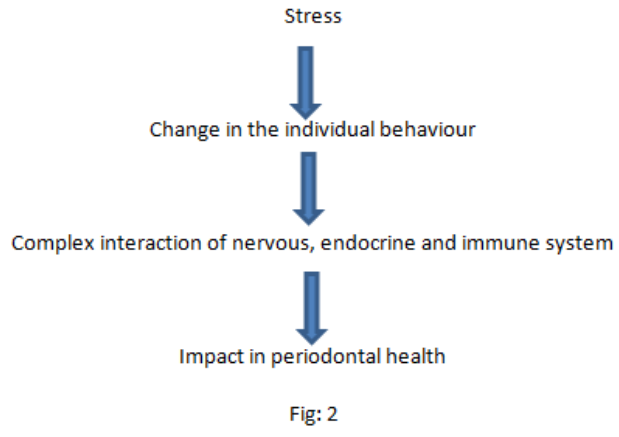

\subsection{Health impairing behaviour and periodontal diseases:}

1 Neglected oral hygiene- increase plaque accumulation- gingival inflammation ((Deinzer and co-workers) ${ }^{4}$.

2 Cigarette smoking- impairs collagen synthesis and increases MMP 8 level

3 Alcohol consumption

4 Disturbed sleeping pattern - decrease in growth hormone- impairs the tissue repair response.

5 Poor nutritional intake can result in impaired wound healing ${ }^{13}$.

6 Other behaviour potentially harmful to the periodontal tissue are difficulty in concentration, bruxism, anxiety (Dworkin 2002).

7 Individual under stress may be less likely to seek for professional care. All these behavioural changes increase their susceptibility to periodontal disease destruction. 


\subsection{Effect of pro-inflammatory cytokines and glucocorticoids in stressful condition:}

IL-1 is also known to activate the HPA leads to a feedback loop ${ }^{8}$. Increase level of IL-1, IL6, cortisol and decrease level of salivary IgA found in gingival crevicular fluid ${ }^{5}$. (Fig.3)

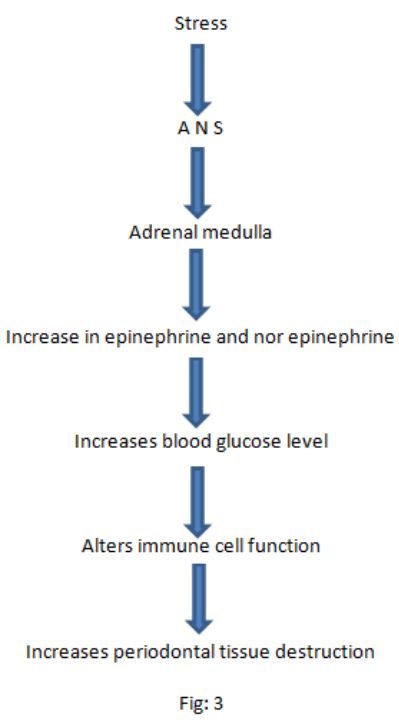

\subsection{Alteration in $\mathbf{T}$ helper I cell/ $\mathbf{T}$ helper II cell ratio:}

Helper T- cell lymphocyte can be divided in to two subpopulation- T helper 1 cell and T helper 2 cell based on their cytokine production.

The effect of the T cell:

T helper 1 cell: stimulates cellular immunity through production of interferon and IL-2.

T helper 2 cell: promote B cell dysfunction and humoral immunity through the release of IL-4, 5, 6, and 10.

Marshall et al demonstrated, a T helper 2 cell responses in medical students during stressful working periods.

\subsection{Effect of stress on wound healing:}

Stress releases highly active hormones like catecholamine, which results in altered blood flow, peripheral vasoconstriction may affect oxygen dependant healing mechanism which impairs wound healing. (Fig. 4)

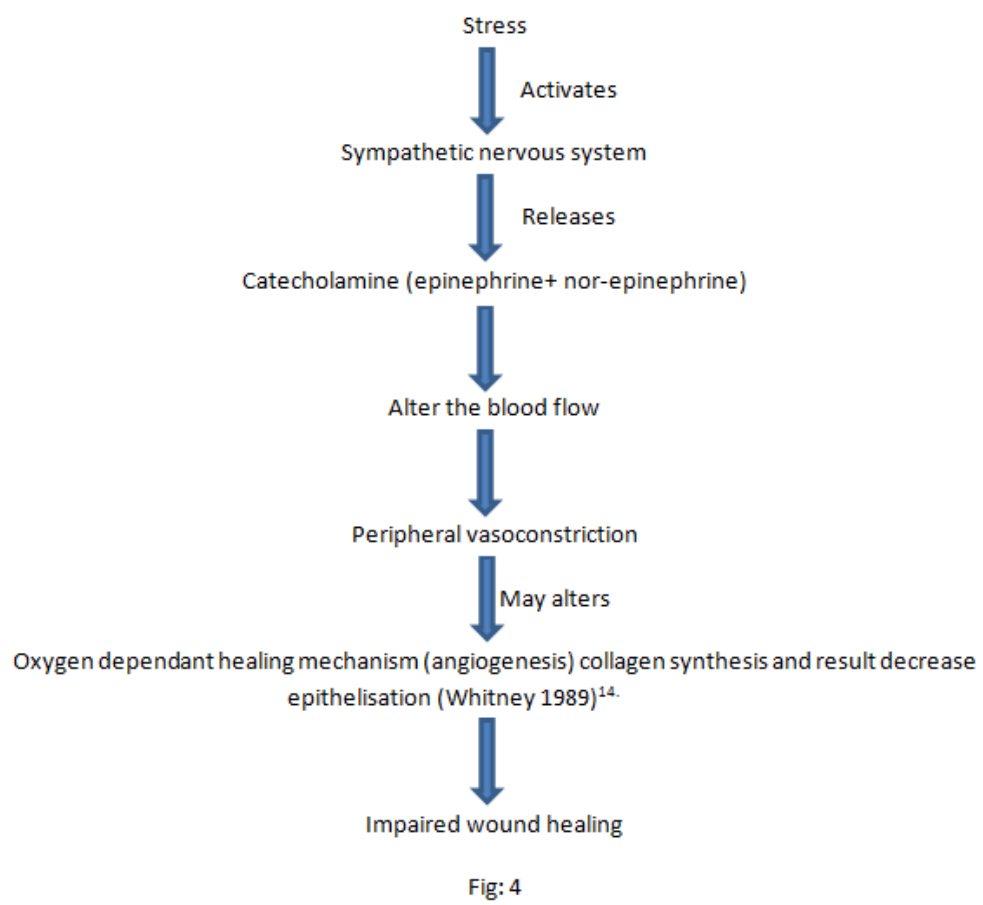


Stress and periodontitis: A review.

\subsection{Altered glucocorticoid level (cortisol) and higher catecholamine level (epinephrine and nor- epinephrine) may lead to any or all of the following:}

1. Hyperglycaemia which impairs neutrophil formation and thus impairs initial phase of wound healing.

2. Decreases level of growth factors which may down regulate tissue repair system.

3. Alters cytokine profile that may affect recruitment of macrophages and fibroblast causes impaired wound remodelling.

4. Decreases the MMP level which impairs tissue turnover and causes decrease in wound healing.

\section{Discussion:}

Continuous exposure to stress affects the body to produce an interrelated non-specific tissue response. But how exactly it affects is not fully understood. Stress may alter the resistance by acting on autonomous nervous system and endocrine system to alter circulatory antibodies and gingival circulation.

Also increase in cortisol level at the time of stress produces alteration in immune system that will impairs the healing after periodontal surgery. The mechanism of stress being risk factor forperiodontal diseases includes psychological, neurological, immunological, behavioural changes or combination of all/ some of them. Stress, depression, and circulatory cortisol correlated with measures of periodontal disease. Epidemiological studies conducted in various countries reported that $5 \%-20 \%$ of any population will have severe forms of periodontitis that affect majority of adult patient with stress, seems to be more likely to have periodontitis than the patient without stress. Reduced cell mediated immunity was observed with patient having stress with life threatening event. In the HPA system, cortisol secretion is regulated by the ACTH from the pitutory gland. Salivary cortisol level is closely same as blood cortisol level and regulates HPA activity. Higher concentrate of hydrocortisone up regulate the expression of 1,2, 7, and 11 and TIMP-1 in human gingival fibers which major contributes a mechanism for periodontal disease associated with stress ${ }^{17}$.

\section{Conclusion:}

Stress can cause behaviour modification (e.g. smoking, alcohol abuse) and immunosuppressant effect (decreased PMN, altered helper T 1 cell/T helper 2 cell ratio ) which may result in greater recurrence of periodontal disease as well as delayed wound healing. Evidence suggested that stress is associated with more severe periodontal disease, as well as healing response to traditional periodontal surgery. But how exactly it's Influence on periodontal disease is not fully understood, further studies are needed.

The role of the dentist is to discuss lifestyle in a broader concept than just oral hygiene; they should be more psychologically oriented. It is very important to understand the patient's situation to help them to maintain a healthy periodontium.

\section{References:}

[1] Dorland. Dorland's Illustrated Medical Dictionary. Oxford, UK: WB Saunders, 2000.

[2] Ader RF, Cohen DLN. Psychoneuroimmunology. San Diego, CA: Academic Press, 2001.

[3] Deinzer R, Granrath N, Stuhl H, Twork L, Idel H, Waschul B, Herforth A. Acute stress effects on local Il-1beta responses to pathogens in a human in vivo model. Brain BehavImmun 2004: 18: 458-467.

[4] Deinzer R, Hilpert D, Bach K, Schawacht M, Herforth A. Effects of academic stress on oral hygiene - a potential link between stress and plaque-associated disease?JClinPeriodontol 2001: 28: 459-464.

[5] Deinzer R, Kleineidam C, Stiller-Winkler R, Idel H, Bachg D. Prolonged reduction of salivary immunoglobulin A (sIgA) after a major academic exam. IntJPsychophysiol 2000: 37: 219-232.

[6] Deinzer R, Kottmann W, Forster P, Herforth A, Stiller- Winkler R, Idel H. After-effects of stress on crevicular interleukin-1beta. $J$ ClinPeriodontol 2000: 27: 74-77.

[7] Deinzer R, Ruttermann S, Mobes O, Herforth A. Increase in gingival inflammation under academic stress. J ClinPeriodontol 1998: 25: 431-433.

[8] Furukawa H, del Rey A, Monge-Arditi G, Besedovsky HO. Interleukin-1, but not stress, stimulates glucocorticoid output during early postnatal life in mice. Ann N Y AcadSci 1998: 840: 117-122.

[9] Genco RJ. Current view of risk factors for periodontal diseases.J Periodontol 1996: 67: 1041-1049.

[10] Genco RJ, Ho AW, Kopman J, Grossi SG, Dunford RG, Tedesco LA. Models to evaluate the role of stress in periodontal disease.Ann Periodontol 1998: 3: 288-302.

[11] Genco RJ, Ho AW, Grossi SG, Dunford RG, Tedesco LA. Relationship of stress, distress and inadequate coping behaviors to periodontal disease. J Periodontol 1999: 70:711-723.

[12] Seyle H. What is stress? Metabolism 1956: 5: 525-530.

[13] Rose M, Sanford A, Thomas C, Opp MR. Factors altering the sleep of burned children. Sleep 2001: 24: 45-51.

[14] Vingerhoets A, Health Psychology. Oxford, UK: Blackwell Publishing, 2004.

[15] Yang EV, Glaser R. Stress-induced immunomodulation and the implications for health IntImmunopharmacol 2002: 2: 315-324

[16] LeResche L, Dworkin SF. The role of stress in inflammatory disease, including periodontal disease: review of concepts and current findings. Periodontol 2000 2002: 30:91-103

[17] Gallacher DV, Petersen OH, stimulus- secretion coupling in mammalian salivary gland, Int. Rev. Physiol-1983; 28: 1-52. 